\title{
Relationship between Parental Involvement and Academic Performance of Senior High School Students: The Case of Ashanti Mampong Municipality of Ghana
}

\author{
Mark Owusu Amponsah ${ }^{1, *}$, Eugene Yaw Milledzi ${ }^{1}$, Eric Twum Ampofo ${ }^{2}$, Martin Gyambrah $^{3}$ \\ ${ }^{1}$ Department of Education and Psychology, College of Education Studies, University of Cape Coast, Ghana \\ ${ }^{2}$ Department of Educational Psychology, College of Education, Ashanti Mampong, Ghana \\ ${ }^{3}$ Department of Business Psychology, University of Applied Management, Accra, Ghana \\ *Corresponding author: mamponsah@ucc.edu.gh
}

\begin{abstract}
The study explored the relationship between parental involvement in education and academic performance of senior high school students in the Ashanti Mampong Municipality of Ghana. The descriptive correlational research design was used to conduct the study. Stratified random sampling procedure was employed to select a total sample of 471 respondents made up of 186 males and 285 females. Questionnaire and test items on Mathematics and English Language were the research instruments used to collect data for the study. Data analysis was conducted by employing descriptive statistical tools (mean and standard deviation scores) to examine students' perceived parental academic ambition and involvement in their education while the Zero-order correlation was used to examine the relationships between parental involvement in education and academic performance. The results of the study show a significant positive relationship between parental involvement in education and students' academic performance. It is recommended from the study that parents should play a leading role in supporting their children's education since they are the first to expose children to the social and academic world.
\end{abstract}

Keywords: Parental involvement, Academic ambition, Academic performance, Education

Cite This Article: Mark Owusu Amponsah, Eugene Yaw Milledzi, Eric Twum Ampofo, and Martin Gyambrah, "Relationship between Parental Involvement and Academic Performance of Senior High School Students: The Case of Ashanti Mampong Municipality of Ghana." American Journal of Educational Research, vol. 6, no. 1 (2018): 1-8. doi: 10.12691/education-6-1-1.

\section{Introduction}

A person's education is closely linked with his or her life chances, income and general well-being. Therefore, the success of students in any academic task has become a major concern to educators, parents, researchers and society. Literature indicates that there is lack of specific or universal definition of academic performance. This is because academic performance is a multidimensional construct composed of the skills, attitudes, and behaviours of a learner that contribute to academic success in the classroom [1]. To other researchers, academic performance is determined by examination grades at the end of a particular term, semester or programme [2]. Higher scores indicate better academic performance. It is a satisfactory and superior level of performance of students as they progress through and complete their school experience. The implication of this definition is underscored by studies which repeatedly demonstrate that the vast majority of students who withdraw from school do so for no reason other than poor academic performance.

Measuring academic performance can occur at multiple levels and serves multiple purposes. For instance, it has been indicated that classroom teachers often conduct formative and summative tests to evaluate student mastery of course content and provide grades for students and parents [3]. Graduation tests in particular are used to determine whether a student has mastered the minimum content and competencies required to receive a high level of education. Each of these kinds of assessments engenders significant questions related to test design, types of decisions supported by the results as well as alternative assessment $[3,4]$.

A number of studies have been conducted to explore the factors that affect academic performance of students in a number of educational institutions. Majority of these studies have focused on parents (family causal factors), teachers (academic causal factors), and students (personal causal factors) [5,6,7]. Even though a combination of these factors influence academic performance of students, they vary from one academic environment to another, from one set of students to the next, and from one cultural setting to another [5]. Individual characteristics such as previous school achievements, academic self-efficacy or study motivation have been identified to correlate with academic performance [8]. Also, socio-economic background with specific reference to parents' education has been shown to have a positive influence on the academic performance of students $[9,10,11]$. 


\section{Parental Ambition and Academic Performance}

Parental ambition is what parents hope and want their children to achieve in future. Parents' academic ambitions for their children might influence their children's academic achievements both directly and indirectly [12]. Parents' academic ambition for their children has been identified to have a telling effect on the children's academic performance [13]. The expectancy value theory argues that people judge the instrumentality of possible options, weigh their costs and benefits, and then select the course of action with the highest expected value. Parental expectations, therefore, are wishes about their children's academic achievement and career ambition. Many parents believe that transmitting a sense of high academic ambitions to their children is one way to infuse them with the confidence, self-esteem, and personal standards of merit and value [14].

Empirical studies have reported significant relationships between parental ambitions and psychological adjustment, psychological distress and academic achievement of children $[15,16]$. Other researchers in their studies have established a significant effect of parental ambition on academic success of their children $[17,18]$. It should be noted that parental ambition is one of the extra-curricular factors that might influence children's academic performance. It has been pointed out that parents who have high ambitions for their children to do well in academic matters have children who show most rapid cognitive progress [19]. A similar study found that parents' academic ambition for their children partially mediated the relationships between assets and children's educational achievements showing the significant effect of parental ambitions on education of their children after controlling for family income and other parent characteristics [20].

Although parental ambition is considered as one of the cultural factors affecting academic performance of students, some researchers [18,21] in their studies have reported negative effects such as adjustment problems, psychological distress as well as behaviour problems. They reported that college students experience low level of self-worth and adjustment when higher expectation discrepancies are present between themselves and their parents. Their studies further revealed that parents' academic ambition for their children is one of the basic sources of academic stress in middle and high school students. In contrast, a study in Canada found that parental academic ambition for their children was positively associated with 19 percent of the variance in academic performance [19]. It was argued that parental beliefs influence their children's perceptions of their own abilities, their attitudes, and expectations for academic success and this directly affects the children's cognitive performance [22].

A study on the effects of perceived parental ambitions on the mathematics performance of children established that while taking arithmetic test anticipating parental evaluation and expectation, the performance was better for those who perceived their parents as having higher ambitions for them [23]. Studies continue to give credence to the fact that parents' achievement beliefs, attitudes and values not only guide their behaviour with their children [24], but also appear to have an influence on their children's academic achievement beliefs. For example, it has been indicated that among a group of uniformly high achieving children, perceptions of academic competence were influenced more by parents' ambitions than by the children's record of academic achievement [25]. Similarly, a study found that students' academic expectations have a strong positive association with perceived parental academic ambition particularly with regard to maternal educational goals [26].

\section{Parental Involvement and Academic Performance}

Parental involvement has been defined in various ways by various authors in the literature. For example, typology of parental involvement includes six categories such as basic parenting, facilitating learning at home, communicating with the school, volunteering at the school, participating in school decision making and collaborating with the community [27]. Other authors and researchers in their studies have used a typology of parental involvement that is based on either intuitive appeal or factor analysis of existing data $[28,29]$. It should be noted that studies that did not apply a multifaceted typology of parental involvement tend to either describe it as a one-dimensional construct [30,31] or distinguish it broadly by the context in which it takes place that is, at home or in school [9]. Home-based parental involvement includes helping students with homework, talking with them about school, expressing high expectations, encouraging school success, and providing structures that are conducive for learning $[29,32]$. School-based parental involvement on the other hand includes volunteering at school, participating in school events and school organizations as well as communicating with teachers and school staff [33].

Parental involvement is the degree to which a parent is committed to his or her role as a parent and to the fostering of optimal child development. It typically concerns the amount of effort put into child-oriented education as well as other activities [11]. In the educational domain for example, parental involvement has primarily focused on specific activities such as participating in school events; helping with homework and the number of contacts between families and schools. It has been conceptualized parental involvement in education as the dedication of resources by parents to children within the educational domain [34].

The level of parental involvement has significant effects on children's academic performance. Social cognitive theory suggests that children absorb messages about appropriate behaviour and socially accepted goals by observing and talking with important people in their lives [35]. Based on this assumption, parents have the potential to model positive attitudes and behaviours of their children toward the school. Several researchers in their studies in the developed countries have found that parental involvement contributes to academic success of their children [36,37,38]. This is because children are 
more likely to apply themselves and perform better in school when their parents show an interest in their school work, are willing to assist them with homework and are willing to hold their children accountable for completion of school assignments. Children who are not working hard at school may begin to perceive school as valuable when parents actively demonstrate that they value schooling through involvement.

Besides parents have the distinct advantage over anyone else in that they can provide a more stable and continuously positive influence that could enhance and complement what the school fosters on their children. In this regard, parental involvement is undeniably critical [39]. Research findings suggest that parents' attitudes, together with their behaviour and activities with regard to their children's education have an effect on academic achievement [40]. However, with regard to the content of what children learn, many parents fall short because in general they do not possess the necessary education and therefore find it difficult to determine and understand what was done at school [41]. This is a point also raised by a learner in a related study, “... my parents don't know maths and physics so how can they be involved...?” [39].

Parental involvement is a multidimensional and bidirectional construct that has been shown to have clear links with social and academic outcomes for children. Traditionally, parental involvement has been defined as engaging parents in school-based activities and events related to their child's education [42]. However, a more comprehensive view of parental involvement envisaged in the current study goes beyond just parent activities in school settings but in subject-oriented participations with specific reference to Mathematics and English Language. This comprehensive view of parental involvement is grounded in the understanding that success of students in Mathematics and English Language at the senior high school level is influenced by multiple contexts such as the home, the school, and the community in a dynamic and bidirectional manner.

Several researchers and educators have recognised the important role of a strong positive bond between homes and schools in the development and education of children $[43,44,45]$. Research has also shown that successful students have strong academic support from their involved parents [45]. Similarly, research on effective schools where students are learning and achieving has consistently shown that these schools, despite often working in low social and economic neighbourhoods, have strong and positive school-home relationships [43,45]. More importantly, these effective schools have made a real effort in reaching out to their students' families in order to bring about liaison and cooperation.

It has been hypothesized that parental involvement primarily influences children's attributes and behaviours which in turn affect their achievement in mathematics [46]. Similarly, the theoretical framework provided by Hoover-Dempsey and Sandler [47] suggests that parental involvement enhances academic self-efficacy, intrinsic motivation to learn, self-regulatory use and social self-efficacy of children which in turn operate to enhance academic performance. For example, a study found that parental involvement (home involvement, school involvement, parent-teacher communication) was predictive of children's school engagement and socio-emotional adjustment [48]. Studies have also shown that students performed better academically and have a more positive school attitude if they had parents who are aware, knowledgeable and involved [49].

Conducive learning environments that incorporate meaningful mathematical experiences are associated with higher achievement and genuine home and school collaboration have also been found to lift children's academic performance significantly. Results from a study conducted by Cai [50] indicated that parental involvement is a statistically significant predictor of mathematical achievement and also promoted positive behaviours and emotional development in children. Friedel, Cortino, Turner and Midgley [51] have argued that parental involvement in its many and varied ways is a vital parameter for increasing children's academic achievement.

Empirical studies have indicated that some specific factors that play an essential role in increasing children's mathematics achievement are parental aspirations, parentchild communication, home structure, and parents' involvement in school's activities. For example, [52] in their study reported that students whose parents are educated score higher on standardized tests than those whose parents were not educated. This is because educated parents can better communicate with their children regarding the school work, activities and the information being taught at school. They can better assist their children in their work and participate at school. Therefore, academic performance of students heavily depends upon the parental involvement in their academic activities to attain the higher level of quality in academic success.

However, few studies that differentiate between home and school-based parental involvement reported contradictory findings. For example, in some studies home-based parental involvement has significant positive effect while in other studies, school-based involvement has significant negative effects related to academic outcomes. It can be argued that the interventions promoting parental involvement vary based on the context in which the involvement occurs. The empirical literature so far has shown that parental involvement is consistently related to a child's increased academic performance but the specific mechanisms through which parents exert their influence on a child's academic performance are yet not fully understood.

From the literature, we also observed that while the relationship between parental involvement and children's academic performance is well established at the lower level of education, researchers in the area have not yet fully explored how parental involvement is related to students' academic performance in Mathematics and English Language at the senior high school levels. Parents are usually very much involved in their children's early education but this involvement tends to decrease when children proceed to high school [53]. Therefore, the present study on the relationship between parental involvement and academic performance of senior high school students in Ghana is an attempt to fill this lacuna.

\section{Purpose of the Study}

The purpose of this study was to examine the relationship between parental involvement and academic 
performance of senior high school students in Mathematics and English Language. Specifically, the study sought to explore:

1. How senior high school students perceive their parents' academic ambition.

2. How senior high school students perceive their parents' academic involvement.

3. How parental ambition relates to students' academic performance.

4. How parental involvement relates to student's academic performance.

\section{Research Questions}

The following research questions guided the study:

1. How do senior high school students in the Ashanti Mampong Municipality of Ghana perceive their parents' academic ambition?

2. How do senior high school students in the Ashanti Mampong Municipality of Ghana perceive their parents' academic involvement?

3. What is the relationship between parents' academic ambition and students' academic performance in Mathematics and English Language?

4. What is the relationship between parental involvement and students' academic performance in Mathematics and English Language?

\section{Methodology}

\subsection{Research Design}

The study utilised the quantitative research design approach. Specifically, a descriptive correlational research design was employed to examine the relationship between parental involvement and academic performance of Senior High School students. It is noted that, correlational research describes an existing relationship between variables [54]. Correlational research design, was therefore, used for this study since the objective of the study was to assess how the independent variables (parental academic ambition and parental involvement) relate to the dependent variable (students' academic performance). In selecting a method to conduct the descriptive correlational study, a survey method was chosen to collect data from the respondents.

\subsection{Population and Sample}

The target population for the study was Senior High School students in the Ashanti Mampong Municipality of Ghana while the accessible population was day form two students comprising one thousand seven hundred and fourteen $(1,714)$ students. The researchers purposively selected form two day students to participate in the study because the form two students have been in the school for more than a year and stood a better chance of providing useful information. There are four government Senior High Schools in the municipality namely St. Joseph Senior High School; St. Monica's Senior High School; Amaniampong Senior High School and Kofiase Senior
High School. Based on the population of students in the schools, each school was assigned a quota. Stratified as well as simple random sampling procedures were used to select a total sample of 471 students made up of 186 males and 285 females.

\subsection{Data Collection Instruments}

The instruments for collecting data in this study were the questionnaire and test items based on the form two Mathematics and English Language syllabuses of Senior High Schools. The questionnaire comprised three sections namely A, B and C. Section A discusses the demographic profile of the respondents such as age, sex and educational background of parents. Section B consists of items that measure parental ambition dimensions. Finally, items on Section $\mathrm{C}$ were designed to measure students' perceptions on parental involvement dimensions. Sections B and C were designed on a six-point Likert scale to seek for information on the predictor variables. The test items in Mathematics and English Language were constructed by using the SHS two syllabuses in these two subjects. Each subject contained twenty-five (25) multiple-choice items and thirty (30) minutes each was given to respondents to complete the test. The test was scored over hundred (100). The scores helped the researchers to know how well the respondents performed in these two subjects. The maximum scores were $95 \%$ and $85 \%$ for English Language and Mathematics respectively.

\subsection{Validity and Reliability}

The instruments for data collection were therefore subjected to content analysis. Validity of the questionnaire was obtained by presenting it to three experts in test construction. Also, the validity of the Mathematics and English Language test items was obtained through scrutiny by two Mathematics and English Language professors in the University of Cape Coast. A pre-test was conducted among form two-day senior high school students from Nsutaman SHS; Jamasi STHS and Odiko Boatemaa SHS. These schools were selected because they are found in the same geographical precinct, and therefore share similar characteristics with the sampled schools. The Cronbach Alpha reliability was 0.87 . Again, the reliability of the test items was established by presenting it to two raters to score a respondent paper. This showed the index of the extent to which the raters were consistent in rating the same respondent.

\subsection{Data Collection Procedure}

Permission to conduct the study was obtained from the heads of the institutions selected for the study. The researchers arranged a session with all the respondents selected for the study. The purpose of the study was explained to the respondents. The administration and collection of the data was done by the researchers with the help of two research assistants who were trained on the procedures involved in the administration and collection of the questionnaires and the test items. The questionnaires were administered first and two weeks later the test items in Mathematics and English Language were 
also administered. The return rate of the research instruments was hundred (100) percent.

\subsection{Ethical Considerations}

With regard to ethical measures, a written permission was obtained from the respective Senior High Schools sampled for the study. Ethical clearance to conduct the research was obtained from the Institutional Review Board of the University of Cape Coast. The participants were informed and asked to sign a consent form and participation in the study was voluntary. Confidentiality was maintained during data collection. Names of individuals were not used and numbers were assigned to the participants during the data collection.

\subsection{Data Analysis Procedure}

The returned questionnaires were coded and data cleaning was conducted to examine the questionnaires for duplications and missing values. For data analysis, the responses to the questionnaires were analysed using the Predictive Analytic Software (PASW) Version 19.0. Analysis for research questions 1 and 2 was conducted by employing descriptive statistical tools to examine the mean and standard deviation scores for students' perceived parental ambitions and parental involvement. For research questions 3 and 4, the Zero-order correlation was employed to examine the relationships between parental ambition and academic performance as well as the relationships between parental involvement and academic performance among senior high school students.

\section{Results and Discussion}

Various researchers in education have used different rating scales to measure academic performance [1,7]. The argument is that academic performance of students can occur at multiple levels and serves multiple purposes. In this study, however, the students' academic performance was measured by the scores on Mathematics and English Language tests designed by the researchers. This provides credence to what was reported by Elliot [3] that classroom teachers often conduct formative and summative tests to evaluate mastery of course content and provide grades for students and parents. The test instruments were crafted to cover topics that were believed to have been already treated. In all, two separate tests were designed in Mathematics and English Language. Each contained 25 multiple-choice items. The scores of the tests were measured on a six-point Likert scale with the mean cut-off point of 3.5. Table 1 shows the students' performance in the Mathematics and English Language tests.

Table 1. Mathematics and English Language Tests Scores of Students

\begin{tabular}{lcc}
\hline Test & Mean & Std. Dev. \\
\hline Mathematics & 4.181 & .481 \\
English Language & 4.351 & .482 \\
\hline
\end{tabular}

$\mathrm{N}=471$
The results in Table 1 show that most of the respondents performed above average in both subjects. This creates the impression that majority of the students performed well in both Mathematics and English Language tests.

Research question 1 sought to explore how students of senior high schools in the Ashanti Mampong Municipality of Ghana perceived their parents' academic ambition. Five items measured on a six-point Likert scale were used to solicit their responses. Prior to data analysis, a test of normality was performed and based on the findings that emerged from the normality test, the mean and standard deviations were used to analyse the data. Also, the mean and standard deviation were used based on the six-point numerical scale employed. The average response cut-off score used in grouping the views of respondents with regard to positive/agree and negative/disagree was a mean score of 3.5 . That is $(1+2+3+4+5+6) / 6=3.5$. The results are presented in Table 2.

Table 2. Students' Perceived Parental Academic Ambition

\begin{tabular}{lccc}
\hline Statements & Mean & SD \\
\hline My parents always set high academic standard for me & 5.35 & .781 \\
My parents encourage me to set high academic goals & 5.36 & .682 \\
My parents always tell me the benefits of education & 5.38 & .713 \\
My parents expect me to attain the highest education & 5.37 & .758 \\
My parents feel proud when I do well in school & 5.53 & .686 \\
\hline
\end{tabular}

$\mathrm{N}=471$

The results in Table 2 show a positive students' perceived parental academic ambition since all the values are above 3.5 which is the established cut-off mean score for negative and positive students' perceived parental academic ambitions. The results imply that parents in Ashanti Mampong municipality of Ghana have high academic ambitions and expectations for their children in senior high schools and this is confirmed by the standard deviations which show little variations in the respondents' views. Parental academic ambitions as indicated by Jeynes [38] reflect the degree to which parents presume that their children will perform well in school, now and in the future. The findings of this study is consistent with the assertion of Smith and May [26] that parents can increase the potential educational achievement of their children by setting high academic ambitions or expectations which are positively perceived on the mean score ('my parents always set high academic standard for me' and my parents expect me to attain the highest level of education') which also corroborates the findings of Belsky [15] who in a study found that academic performance of students was heavily depended upon positive perceived parental academic ambitions or expectations.

The reason for the positive perceived parental academic ambition by students in this study is probably due to the fact that parents who are educated know the learning requirements and have the opportunity to provide the best educational environments for their children. This is in line with the works of $[7,52]$ that parents' academic ambitions can increase the potential development of their children's 
educational knowledge and skills through the provision of stimulating learning environments.

The study further sought to assess the views of students on how they perceived their parents' involvement in their education. To achieve this objective, Research Question 2 was evaluated. In all, six items were used to elicit information on this variable. Again, the average cut-off score used for positive/agree and negative/disagree was the mean score of 3.5. Table 3 presents the results.

Table 3. Students’ Perceived Parental Involvement in Education

\begin{tabular}{lcc}
\hline Statements & Mean & SD \\
\hline My parents monitor my studies at home & 5.28 & .835 \\
My parents monitor my school performance & 5.30 & .788 \\
My parents encourage me to take my studies seriously & 5.39 & .749 \\
My parents provide me with material supports & 5.31 & .809 \\
My parents allot time for me to do my homework & 4.71 & 1.352 \\
My parents always provide me with emotional support & 4.85 & 1.269 \\
\hline
\end{tabular}

$\mathrm{N}=471$

As shown in Table 3, the mean scores of the various items suggest that senior high school students in the Ashanti Mampong municipality of Ghana perceived their parents to be much interested and involved in their education. The values show a high positive students' perceived parental involvement on the six-point Likert scale established because 3.5 was the established cut-off between negative and positive students' perceived parental involvement. The foregoing gives credence to what was revealed by $[47,48]$ that parents provide encouragement and monitor their children's studies at home which are on the high side of the mean ('my parents encourage me to take my studies seriously' and 'my parents monitor my studies at home'). Again, the outcome of this study underscores the relevance of parental involvement in education reported by [51,52] in line with the emotional as well as the material support parents provide to their children.

Zhan [20] noted that parental involvement in its many and varied ways is a vital parameter for increasing children's educational aspirations. The current study has indicated that some specific factors such as parent-child communication, providing material as well as emotional support and monitoring of children's learning at home play an important role in increasing children's academic achievement as previously found out by $[28,38]$ that a positive relationship exists between at-home parental involvement and a range of school related outcomes including academic achievement, school engagement and socio-emotional adjustment.

To examine the relationship between parental academic ambition and students' performance in Mathematics and English Language, the Zero-order correlation was employed. In order to achieve the objective on Research Question 3, a total score was calculated for the five items that constituted the variable (parental academic ambition) which were measured on a six-point Likert scale. The results are presented in Table 4.
Table 4. Relationship between Parental Academic Ambition and Students' Performance in Mathematics and English Language

\begin{tabular}{cccc}
\hline & & $\begin{array}{c}\text { Performance } \\
\text { in Mathematics }\end{array}$ & $\begin{array}{c}\text { Performance in } \\
\text { English }\end{array}$ \\
\hline Parents’ Aca. Ambi. & Pearson & $.261^{* *}$ & $.268^{* *}$ \\
& Sig. & .000 & .000 \\
& $\mathrm{~N}$ & 471 & 471 \\
\hline
\end{tabular}

**. Correlation is significant at the 0.01 level (2-tailed).

With reference to the results in Table 4, the Zero-order correlation coefficients for Mathematics and English Language are $\mathrm{r}=0.261^{* *}$ and $\mathrm{r}=0.268^{* *}$ respectively. The coefficients are both positive with significance or pvalue $=0.000$ which is less than alpha $=0.01$ denoting that parents' academic ambition was significantly related to students' performance in Mathematics and English Language. This finding confirms the results of some previous studies that have established a positive relationship between parental academic ambition and students' performance [20,45]. According to Fan and Williams [7], parents who have high expectations for their children to do well in academic matters have children who showed most rapid cognitive progress. This also gives credence to what was reported in a study by Maurin [19] that parental academic ambitions for their children were associated with 19 percent of the variance in the children's academic performance.

The outcome of the current study creates the impression that parental academic beliefs for their children influence the children's perceptions of their own abilities, their attitudes as well as expectations for success. According to Alexander and Entwisle [24], parents' beliefs, attitudes and values do not only guide their behaviour with their children but also appear to relate with their children's achievement beliefs. This is consistent with the findings of Phillips [25] who in a study reported that among a group of uniformly high achieving children, perceptions of their academic performance were related more with parents' ambitions than with children's past records of academic achievement.

Research Question 4 sought to explore the relationship between parental involvement and academic performance of students in mathematics and English Language. The six items that made up parental involvement were summed up and measured on a six-point Likert scale. Zero-order correlation coefficients between parental involvement and students' performance in Mathematics and English Language were generated to show the direction and strength of the relationship. The results are depicted in Table 5.

Table 5. Relationship between Parental Involvement and Students' Performance in Mathematics and English Language

\begin{tabular}{cccc}
\hline & & $\begin{array}{c}\text { Performance } \\
\text { in Mathematics }\end{array}$ & $\begin{array}{c}\text { Performance } \\
\text { in English }\end{array}$ \\
\hline Involvement & Pearson & $.433^{* *}$ & $.477^{* *}$ \\
Sig. & .000 & .000 \\
$\mathrm{~N}$ & 471 & 471 \\
\hline
\end{tabular}

**. Correlation is significant at the 0.01 level (2-tailed). 
As shown in Table 5, the Zero-order correlation coefficients obtained for Mathematics and English Language were $r=0.433^{* *}$ and $r=0.477^{* *}$ respectively. Both are positive with significance or $\mathrm{p}$-value $=0.001$ which is less than alpha $=0.01$, which implies that parental involvement was significantly related to academic performance in Mathematics and English Language. The findings of the current study give prominence to the view that if parents monitor and encourage their children to be serious with their studies, academic performance of students will be high. The findings also point to the fact that parents' attitudes together with their behaviour and activities with regard to their children's education have an effect on academic achievement. This is because children are more likely to do well in school when their parents show an interest in their school and are willing to hold them accountable for completion of school assignment.

The findings of this study go a long way to give credence to the social cognitive theory which suggests that children absorb messages about appropriate behaviour and socially accepted goals by observing and talking with important people in their lives [35]. The results of the current study further point out to the fact that parents have the potential to model positive attitudes and behaviours of their children towards the school which also corroborates Mji and Makgato [39] assertion that parents have the distinct advantage over anyone else because they are likely to provide a more stable and continuously positive influence that could enhance and complement what the school fosters on their children. No doubt in the current study, parental involvement is significantly related to students' academic performance in Mathematics and English Language. This is also in line with previous works that reported similar findings. For example, Giallo, Treyvaud, Matthews and Kienhuis [55] in their study have concluded that parental involvement such as parenting style, stable and secure environment, intellectual stimulation, parent-child discussion, contact with school as well as participation in school activities have a strong and positive relationship with the child's level of academic performance; thus the more the parental involvement, the higher the academic achievements.

The findings of this study have underscored the strong positive bond between homes and schools in the development and education of children which confirms Hoover-Dempsey and Sandler [47] argument that parental involvement enhances academic self-efficacy, intrinsic motivation to learn as well as self-regulation which in turn operates to enhance academic performance of students. The foregoing, therefore, is in line with Guy et al., [46] who in their theoretical model hypothesized that parental involvement primarily influences children's attributes and behaviours which in turn affect their achievement in Mathematics and English Language which is also consistent with $[36,37,38]$ who in their studies found that parental involvement is significantly related to the academic success of students.

\section{Conclusion and Recommendations}

The findings from the study have led to the conclusion that there is a significant positive relationship between parental involvement and students' academic performance. This suggests that parents' involvement through home works, creating conducive home environment for studying, motivating and setting realistic and high expectations for children enhances academic performance. From the findings and conclusion, it is recommended that parents should play a leading role in supporting their children's education since they are the prime educators and the first agents of socialization that expose children to the social and academic world. Parents should set high and realistic expectations for their children's educational attainment. These high and realistic expectations will motivate their children to perform well academically. Parents should also ensure home supervision by establishing and enforcing the rules and regulations regarding school and home activities as well as providing opportunities and environment conducive for learning. Again, Parent-Teacher Association (PTA) should encourage and educate illiterate parents and help parents with disability nominate a person from the immediate family to support their wards.

\section{References}

[1] Hijazi, S. T., \& Naqvi, S. M. (2006). 'Factors affecting students' performance: A case of private colleges'. Bangladesh E-Journal of Sociology, 3 (1), 65-99.

[2] Tinto, V. (1993). Limits of theory and practice in student attrition. Journal of Higher Education, 53, 687-700.

[3] Elliot, A. (2007). A conceptual history of the achievement goal construct. In A. Elliot \& C. Dweck (Eds.), Handbook of competence and motivation (pp.52-72). New York: Guilford Press.

[4] Johnson, V. E. (2003). Grade inflation: A crisis in college education. New York, NY: Springer-Verlag.

[5] Diaz, A. L. (2003). Personal, family academic factors affecting low achievement in secondary school. Electronic Journal of Research in Educational Psychology and Psychopedagogy, 1(1), 43-66.

[6] Georgiou, S. N. (2007). Parental involvement: Beyond demographics. International Journal of Parents in Education, 1, 59-62.

[7] Fan, W., \& Williams. C. M. (2010). The effects of parental involvement on students' academic self-efficacy, engagement and intrinsic motivation. Educational Psychology, 30(1), 53-74.

[8] Anderson, B., Benjamin, H., \& Fuss, M. A. (1994). The determinants of success in university introductory economics courses. Journal of Economic Education, 25, 99- 119.

[9] Jeynes, W. H. (2003). A meta-analysis: The effects of parental involvement on minority children's academic achievement. Education and Urban Society, 35, 202-218.

[10] McMillan, J., \& Western, J. (2000). Measurement of socialeconomic status of Australian higher education students. Higher Education, 39(2), 25-53.

[11] Nyarko, K. (2011). Parental school involvement: The case of Ghana. Journal of Emerging Trends in Education Research and Policy Studies, 2(5), 378-381.

[12] Bandura, A. (2005). The evolution of social cognitive theory. In K.G. Smith \& M.A. Hitt (Eds.), Great minds in management (pp. 9-35). Oxford:University Press.

[13] Osiki, J. O. (2001). Effects of remedial training programme on the management of learning acquisition defectiveness and poor study habits problems of selected subjects in a community grammar school. Journal of Applied Psychology, 6 (2) 107-115.

[14] Santrock, J. W. (2007). Adolescence. New Delhi: McGraw Hill.

[15] Belsky, J. (1990). Parental and non-parental child care and children's socio-emotional development. A decade in review. Journal of Marriage and Family, 52, 885-903.

[16] Lin, H. (1999). Mother's beliefs, goals and child-rearing behaviours. An analysis of the themes. Review in Applied Psychology, 2, 143-180. 
[17] Wang, L. F., \& Heppner, R. P. (2002). Assessing the impact of parental expectation and psychological distress in Taiwanese college students. The Counselling Psychologists, 30, 582-608.

[18] Agliata, R., \& Renk, S. (2007). College students' adjustments: The role of parent college student expectation discrepancies and communication reciprocity. Journal of Youth and Adolescence, 37, 967-982.

[19] Maurin, E. (2002). "The impact of parental income on early schooling transitions: A re-examination using data over three generations”. Journal of Public Economics, 85 (3), 301-332.

[20] Zhan, M. (2006). Assets, parental expectations and involvement, and children's educational performance. Children and Youth Services Review, 28(8), 961-975.

[21] Shumox, L., \& Lomax, R. (2001). Parental efficacy: Predictor of parenting behaviour and adolescent outcomes. Journal of Parenting, 2(2): 127-150.

[22] Hill, L. J. (1990). Effort and reward in college: A replication of some puzzling findings. Journal of Social Behaviour and Personality, 5, 151-161.

[23] Harackiewicz, J. M. (1996). Approach and avoidance achievement goals and intrinsic motivation: A meta-analysis. Journal of Personality and Social Psychology, 70, 461-475.

[24] Alexander, K. L., \& Entwisle, D. R. (1988). The schooling process in first grade: Two sample a decade apart. American Educational Research Journal, 23, 587-613.

[25] Phillips, L. M. (1987). Effect of early literacy intervention on kindergarten achievement. New York: NY: Andrew Mellon Foundation.

[26] Smith, A. B., \& May, H. (2006). Early childhood care and education in Aotearoa - New Zealand: Melhuish.

[27] Epstein, J. L. (1995). School and family connections: Theory, research and implications for integrating sociologies of education and family. Marriage and Family Review, 15, 99-126.

[28] Izzo, C. V., Weissberg, R. P., Kasprow, W. J., \& Fendrich, M. (1999). A longitudinal assessment of teacher perceptions of parent involvement in children's education and school performance. American Journal of Community Psychology, 27, 817-839.

[29] Sui-Chu, E. H., \& Willms, J. D. (1996). Effects of parental involvement on eighth-grade achievement. The Sociological Quarterly, 69, 126-141.

[30] McCarron, G., \& Inkelas, K. (2006). The gap between educational aspirations and attainment for first-generation college students and the role of parental involvement. Journal of College Student Development, 47(5), 534-549.

[31] Oyserman, D., Brickman, D., \& Rhodes, M. (2007). School success, possible selves, and parent school involvement. Family Relations, 56, 479-489.

[32] Altschul, I. (2012). Linking socioeconomic status to academic achievement of Mexican youth through parent involvement in education. Journal of the Society for Social Work and Research, 3, 13-30.

[33] Mau, W. (1997). Parental influences on the high school student's academic achievement: A comparison of Asian immigrants, Asian Americans, and White Americans. Psychology in the Schools, 34(3), 267-277.

[34] Epstein, J. L. (2005). School-initiated family and community partnerships. In T. Erb (Ed.), This we believe in action: Implementing successful middle level schools (pp. 77-96). Westerville, OH: National Middle School Association.

[35] Bandura, A. (1977). Self-efficacy: Toward a unifying theory of behavioural change. Psychological Review, 84, 191-215.

[36] Fan, X., \& Chen, M. (2001). Parental involvement and students' academic achievement: A meta-analysis. Educational Psychology Review, 13(1), 1-23.
[37] Houtenville, A., \& Conway, K. S. (2008). Parental effort, school resources, and student achievement. Journal of Human Resources, 43(2), 437-453.

[38] Jeynes, W. H. (2007). The relationship between parental involvement and urban secondary school student academic achievement: A meta-analysis. Urban Education, 42(1), 82-110.

[39] Mji, A., \& Makgato, M., (2006). Factors associated with high school learners' poor performance: A spotlight on mathematics and physical science. South African Journal of Education, 26(2), 253-266.

[40] Guolaug, G. (2010). Effects of parental involvement in education: A case study in Namibia. Unpublished PhD dissertation, Faculty of Education Studies, University of Iceland.

[41] Mji, A., \& Mbinda, Z. (2005). Exploring high school science students' perceptions of parental involvement in their education. Psychological Reports, 97, 235-336.

[42] Epstein, J. L. (2001). School, family, and community partnerships: Preparing educators and improving schools. Boulder, CO: Westview Press.

[43] Sanders, M. G., \& Sheldon, S. B. (2009). Principals matter: A guide to school, family, and community partnerships. Corwin: A SAGE Company.

[44] Richardson, S. A. (2009). Principal's perceptions of parental involvement in urban districts of Ohio. Research in the Schools, 16(1), 1-12.

[45] Sheldon, S. B. (2009). In School, family, and community partnerships: Your handbook for action (3rd ed.). USA: Corwin Press.

[46] Guy, R., Tali. R., \& Mordechai, B. (2008). Mothers’ parenting practices and adolescents' learning from their mistakes in class: The mediating role of adolescent's self- disclosure. Journal of Learning and Instruction, 19, 506-512.

[47] Hoover-Dempsey, K. V., \& Sandler, H. M. (1997). Why do parents become involved in their children's education? Review of Educational Research, 67(1), 3-42.

[48] Chowa, G., Masa, R., \& Tucker, J. (2013). The effects of parental involvement on academic performance of Ghanaian youth: Testing measurement and relationship using structural equation modeling. Children and Youth Services Review, 35(12), 65-72.

[49] Anthony, G., \& Walshaw, M. (2009). Characteristics of Effective Teaching of Mathematics: A View from the West. Journal of Mathematics Education, 2(2), 147-164.

[50] Cai, J. (2003). Investigating parental roles in students' learning of mathematics from a cross-national perspective. Mathematics Education Research Journal, 15(2), 87- 106.

[51] Friedel, J., Cortina, K. S., Turner, J. C., \& Midgley, C. (2010). Changes in efficacy beliefs in mathematics across the transition to middle school: Examining the effects of perceived teacher and parent goal emphases. Journal of Educational Psychology, 10, 102-114.

[52] Farooq, M. S., Chaudhry, A. H., Shafiq M. \& Berhanu, G. (2011). Factors affecting students' quality of academic performance: A case of secondary school level. Journal of Quality and Technology Management, 7 (2), 1-14.

[53] Shinn, K. (2002). Luring high school parents onto our turf. The Education Digest, 67(3), 34-36.

[54] Fraenkel, J. R., \& Wallen, N. E. (2000). How to design and evaluate research in education (4th ed.). Boston: McGraw Hill.

[55] Giallo, R., Treyvaud, K., Matthews, J., \& Kienhuis, M. (2010). Making the transition to primary school: An evaluation of a transition programme for parents. Journal of Educational and Developmental Psychology, 10, 1-17. 